compared the stability range of wool keratin to the stability of protein aggregates described by Svedberg. ${ }^{3}$ For serum albumin, the stability found by the ultracentrifuge extends from $p \mathrm{H} 4$ to 9 ; for serum globulin from 4 to 8 -this range is remarkably like the range of osmotic stability found in protein tissue.

Since osmotic swelling may, with considerable justification, be attributed to the formation of a colloidal ion by the protein, due to the formation of charge centres at the free amino or carboxyl groups, it appears that most native proteins have a tendency to form oriented aggregations so arranged that the attraction between the opposite charge centres is at a maximum. In other words, the molecules form cross linkages which are not readily opened up by slight changes in hydrogen ion concentration, and a stability region of $p \mathrm{H}$ becomes apparent. This molecular structure is not, however, stable towards all forces causing hydration of the protein. Collagen fibres resemble gelatin in showing marked swelling in salt solutions over the region between the iso-electric point and absolute neutrality. Keratin and silk fibroin do not show this salt action, possibly because the side spacings between the long protein molecules are so small that even the small molecules of electrolytes find difficulty in penetrating.

\section{JoRdAN LLOXd.}

The Laboratories of the British Leather Manufacturers' Research Association, May 25.

1 D. Jordan Lloyd, Proc. Roy. Soc., B, 89, 277 ; 1917.

NATURE, 127, $665 ; 1931$.

\section{The Velocity of Light}

In Nature for April 4, 1931, M. E. J. Gheury de Bray points out that the determinations of the velocity of light made in this century seem to tend towards smaller and smaller values the more recent the time of observation.

In this connexion the following remarks on the measurement of the standard metre in terms of the wave-length of the red cadmium line may be of interest. If $L$ and $f$ represent, respectively, the length of the metre and the number of wave-lengths, $\lambda$, contained in it, we may write

$$
L=f_{1} \lambda_{1}=f_{2} \lambda_{2}
$$

where the subscripts 1 and 2 refer to two different epochs. It is assumed that there is no intrinsic change in $L$ between the two observations. If we also suppose that the frequency of the light, $v$, has remained constant but that $c$ has varied, then

whence

$$
\lambda_{1}=\frac{c_{1}}{v}, \lambda_{2}=\frac{c_{2}}{v}, \quad . \quad . \quad .
$$

$$
\frac{f_{1}}{f_{2}}=\frac{c_{2}}{c_{1}}
$$

Since the figures quoted by Mr. de Bray show a decrease in $c$ of about $200 \mathrm{~km}$./sec. between 1902 and 1928, an amount many times larger than most of the indicated probable errors, there may be a real difficulty. With this in mind, it is of interest to see what can be obtained from equation (3). So far as I am aware, there have been two determinations of the standard metre in terms of the red cadmium wavelength, and, quite recently, a similar measurement of the standard yard, by Tutton. ${ }^{1}$ The observations on the metre, quoted by Tutton, are

Michelson . . . $1,553,163 \cdot 50\left(f_{1}\right) \quad 1892$

Fabry, Perot, and Benoit 1,553,164.13 $\left(f_{2}\right) \quad 1906$

During the interval of fourteen years $c$ would have changed by something like $1 / 3000$, if its present apparent rate of decrease were constant. The difference in the two values of $f$ is, however, negligible, and, moreover, Tutton's own measurements on the yard, when converted to the metre by a factor obtained by non-interferential methods, very strongly support the conclusion that the number of wavelengths of a given line contained in a given length does not vary with the time.

Thus, taking all the observations at their face value, the situation is that $f_{1}=f_{2}$ while $c_{1} \neq c_{2}$. From these it follows that $\nu$ must depend on the time in a manner such that $c_{1} / \nu_{1}=c_{2} / \nu_{2}$. Since in classical dispersion theory the index of refraction depends on the ratios of the frequency of the incident light to the natural frequencies of the charges in the body, this last relation might be expected to give rather curious results when observations are made from time to time with a prism spectrograph. None, however, has been reported.

If $c$ does ultimately turn out to be constant, it will be important to investigate the discrepancies between the values hitherto published, in order that they may be used in the final mean. On the other hand, if $c$ depends on the time, we may not unreasonably expect such a variation to appear in experiments other than those which give direct measurements of the velocity. OLIN C. Wirson.

Carnegie Institution of Washington, Mount Wilson Observatory, May 10.

I Phil. Trans. Roy. Soc., A, 230, 293; 1931.

\section{Glimate of Southern Rhodesia}

A Note on the "Climate of Southern Rhodesia" appears in Nature of April 2, page 515, based on the Annual Report of this office for the year 1929-30. This notice of our work is much appreciated, but we regret that "E. V. N." has based a revival of the ' south-east trades' theory on the published rainfall maps.

Forecasts based on daily weather maps have been issued by this office for the last ten years. The general rains are of monsoonal character and are associated with the onset of north to north-easterly winds between the semi-permanent high of the Moçambique Channel and the equatorial low in the west.

Recent extension of the weather map has indicated that these winds traverse the tropical portion of the Indian Ocean. The humid north-easterly winds are interrupted from time to time by the invasion of cold air from the south-east in front of a high advancing up the east coast. The zone of discontinuity has marked frontal characteristics, and its passage is accompanied by squalls and thunderstorms, frequently succeeded by drizzle. These highs usually become stationary with their centres near $20^{\circ} \mathrm{S}$. latitude, and give spells of fine weather, with light east winds. Apart from the precipitation at the discontinuity formed by the onset of the south-east winds, the rain associatcd with these winds is purely orographic and small in amount.

The presence of tropical cyclones near Madagascar is usually associated with a diminution of rain in Southern Rhodesia, apparently due to the interruption of the rain-bearing air currents, but a local cyclone which created havoc at Beira in 1929 was undoubtedly the prime cause of a period of heavy rain so far inland as Livingstone.

Noel P. SEllick

Irrigation Division,

(Meteorologist).

Department of Agriculture,

Salisbury, Southern Rhodesia, April 23.

No. 3270 , VoL. 130] 